\title{
Mathematics for photonics education
}

Leno Pedrotti, Gary Beasley, James Sherman

Leno S. Pedrotti, Gary Beasley, James P. Sherman, "Mathematics for photonics education," Proc. SPIE 9664, Ninth International Topical Meeting on Education and Training in Optics and Photonics, 96641X (24 October 2005); doi: $10.1117 / 12.2207677$

SPIE Event: Ninth International Topical Meeting on Education and Training in Optics and Photonics, 2005, Marseille, France 
Ref ETOP023

\title{
Mathematics for Photonics Education
}

\author{
Leno S. Pedrotti ${ }^{1}$, Gary Beasley ${ }^{2}$, James P. Sherman ${ }^{3}$
}

1. Center for Occupational Research and Development (CORD), Waco, TX 76710

2. Central Carolina Community College, Lillington, NC 27546

3. Indiana University of Pennsylvania, Armstrong Campus, Kittanning, PA 16201

\begin{abstract}
The successful completion of two-year AAS photonics technician programs requires a working knowledge of certain mathematics skills. This paper identifies those key skills and describes available learning materials--titled Mathematics for Photonics Education-developed as a review and study guide to help students strengthen their mathematics abilities. The learning materials are supported by diagnostic assessments designed to help identify areas of mathematics weakness and thereby indicate corrective procedures. The paper concludes with evidence from the field concerning the use and effectiveness of the diagnostic test and learning materials.
\end{abstract}

\section{Keywords}

Photonics, technician education, mathematics skills, diagnostic tests, study-guide materials.

\section{Introduction}

\section{Summary}

Over the past twenty-five years, CORD has developed considerable experience in the laser/electro-optics and photonics area-creating curriculum, conducting workshops, and evaluating student achievement in self-help courses. Based on these experiences, CORD has learned that certain sets of basic mathematics skills are essential for satisfactory progress in mastering the technical content of photonics material found in typical two-year education programs. In general, students entering Associate of Applied Science (AAS) programs come with varying backgrounds in mathematics and wideranging retention levels of mathematics they once learned.

Consequently, to help photonics technicians begin their studies with adequate math skills, CORD has developed a special text-Mathematics for Photonics Education. This text pulls together key topics in algebra, geometry, trigonometry, and graphing, and provides teachers and students with appropriate review and study guide materials designed to strengthen mathematics skills as needed to pursue classroom and laboratory work in photonics. In addition, CORD has developed an entry-level diagnostic assessment instrument which can be administered at the beginning of the two-year program of study to detect areas of weakness. Appropriate corrective measures can then be taken early in the program to fortify the skills requiring more practice.

\section{Learning Materials}

A careful analysis of the mathematics skills required to perform satisfactorily in two-year photonics technician education programs has led us to eleven topical areas listed below: 
- Scientific notation

- Unit conversion

- Introductory algebra

- Powers and roots

- Ratio and proportion

- Exponents and logarithms
- Graphing in rectangular coordinates

- Geometry

- Angle measures in two and three dimensions

- Trigonometry

- Special graphs

The learning materials developed for each of the eleven topical areas includes the following pedagogical outline:

- Learning objectives

- Photonics technician scenario with typical math problem

- Explanation of core math concepts

- Example problems with solutions

- Practice exercises with answers

- Useful information in appendix

Photonics Scenario. The learning objectives for each topic are followed by a photonics scenario--a typical problem that photonics technicians are likely to meet in their studies or in the workplace. The scenario is intended to persuade students of the need for mastery of the mathematics skills covered in the topic under study.

Math Skill Development. The core of the presentation in each of the eleven sections is devoted to an explanation of the appropriate mathematics concerned with the concept under discussion. The concepts and mathematics are woven together to provide the students with the necessary mathematics skills. Example problems are used frequently in the presentation of the mathematical concepts to illustrate the correct use of the mathematics. The core explanatory section closes with a solution to the scenario problem posed at the beginning of the section. At this point, the problem and its solution should be quite understandable to the students.

Practice exercises. The end of each section is devoted to a series of practice exercises. Students are encouraged to work out the practice exercises and then compare their solutions with those given at the very end of the section. In this way, they can reach a certain degree of closure concerning mastery of the material. In general, there are 5 or 6 practice exercises for each section.

\section{Diagnostic Assessment Materials}

As mentioned earlier, students entering a typical two-year AAS program in photonics arrive with varying backgrounds and aptitudes in mathematics. Certainly, formal mathematics courses offered by two-year institutions do provide required foundations in general mathematics skills. Often, however, specific math skills are required before these skills come up in formal mathematics courses, and thus their absence must be addressed in a timely manner. 
Toward this end, an associated assessment instrument containing forty-seven multiple-choice questions and titled "Entering Student Assessment for Mathematics for Photonics Education" has been prepared to assist both students and teachers in determining the students' "mathematics readiness." The 47 questions cover mathematical understanding in handling numbers, simple algebra, simple plane geometry, and skills in graphing. Based on the assessment, the material in Mathematics for Photonics Education can be used to help entering students in several ways:

- The material can be presented as a whole in a "regular class" with teacher lecture and practice sessions, generally not for credit.

- The material can be assigned for appropriate students to "learn on their own" with occasional instructor monitoring and help.

- The material can be used "piecemeal" in a self-learning mode-by students who require review in one or more specific mathematics areas.

- The material can be combined with other mathematics remediation materials

\section{Results from the Field}

The Mathematics for Photonics Technicians learning materials were "field-tested" in two schools in the year 2004-Central Carolina Community College (CCCC) in North Carolina and Indiana University of Pennsylvania (IUP) in Pennsylvania.

\section{IUP Report}

Department Chair James P. Sherman and Instructor Ron Freda used the review and study guide materials in an AAS/BS electro-optics degree program in a course titled "Prelude to Physics" in the Fall of 2004. Of the 9 students involved, 8 had extremely weak to marginal math entry skills. One, a BS degree candidate, had good math skills. Department Chair Sherman reported that:

"All but two of the students passed the course and only one student received an A. By and large, students expressed satisfaction with the Mathematics for Photonics Technicians text. They liked the worked examples and the applications of math topics to photonics problems. One student felt that the text was too easy while the others believed that it was level-appropriate. The instructor also seemed satisfied with the text, although he felt that supplementary material was needed in certain parts of the course. In terms of meeting the needs of our EO program, I believe that the book is level-appropriate for the 2-year student possessing weak math backgrounds. The addition of topics such as Phasors will be a welcome addition to the text, since we utilize the topic in several of our courses."

\section{$\underline{\text { CCCC Report }}$}

Instructor Gary Beasley informed CORD that the review and study guide materials were used at CCCC in conjunction with a first course in photonics, LEO 111, "Lasers and Applications". Enrolled students had average and below-average math skills. In the words of G. Beasley:

"Mathematics for Photonics Education" was integrated into LEO 111 during the spring semester of 2004. It was so successful, and so completely embraced by the students, it has since permanently been made a part of LEO 111. The integration was implemented by assigning the students one chapter a week as an extra homework assignment. Each week, these assignments were graded and reviewed. This approach has significantly reduced the amount of time being spent explaining the use of math tools to solve photonics problems in LEO 111 and higher level core courses." 
Feedback from CCCC students about helpful parts of Mathematics for Photonics Education included:

1. Emphasis for showing units during conversion exercises

2. Step-by-step examples

3. Answers with step-by-step solutions

4. Real world photonics examples

5. Math went hand-in-hand with core course subject matter

6. Strong detailed photonics geometric examples and exercises

7. Excellent reference material in appendices about conversion tables and tips for using scientific calculators.

All students strongly recommended continuing the integration of Mathematics for Photonics Education in LEO 111.

\section{Conclusion}

Most students entering two-year education programs for photonics technicians require a review of certain mathematics skills before beginning their studies. CORD has identified key mathematics skills which technicians should possess at time of entry and has prepared appropriate learning materials to help them achieve these skills. To help students and teachers determine the level of mathematics skills that entering students possess, an assessment instrument has been designed. With the help of this instrument and the related learning materials identified in Mathematics for Photonics Technicians, it is hoped that students can begin a photonics AAS program with the requisite mathematics skills at their disposal. 